\title{
Analysis of the Collapse Gradient of Deep Water Horizontal Wellbore and the Effects of Mud Chemical Activity and Variation in Water Depth
}

https://doi.org/10.2478/sgem-2019-0040

received October 5, 2019; accepted February 2, 2020.

Abstract: Wellbore collapse is an instability-event that occurs at low mud density and leads to unfavorable economic project, reaching billions of US dollars. Thus, it is important to accurately determine its value, especially in deepwater horizontal wellbores. The main reasons for nontrivial problems with such wellbores are evident: the shale encountered are anisotropic in nature and possess planes of weakness; they react with water-based mud, generate osmotic stresses, swell, and fall unto the wellbore bottom, thereby increasing the non-productive time. To this end, salts are added to reduce the collapse tendency, but it is not currently known what amount of salt addition maintains stability, and does not lead to wellbore fracture; in deepwater, the current trend in global warming means there is a future concern to the industry. As the climate temperature increases, more ice melts from the polar region, the seawater expands and the sea level rises. How to incorporate the corresponding effect on collapse gradient is scarcely known. This study captures the major concerns stated above into wellbore stability analysis. Following the classical approach for geomechanical analysis, Mogi-Coulomb criterion was combined with a constitutive stress equation comprising contributions from mechanical and osmotic potentials of mud and shale. A sophisticated industry model was used to consider the deepwater effect. The results show significant reduction in collapse gradient as the water depth increases, also, larger difference between the mud and shale chemical activities represents higher complexities in the wellbore. In addition, the reduction

*Corresponding author: Roland I. Nwonodi, Federal University Wukari, Department of Chemical Science, Nigeria, E-mail: rolandnwonodi@yahoo.com

Adewale Dosunmu, Evelyn Ekeinde, University of Port Harcourt, Department of Petroleum and Gas Engineering, Nigeria in the chemical activities of mud limited to $37.5 \%$ of the initial value can be practically safe.

Keywords: Mogi-Coulomb criterion; collapse gradient; horizontal well; deepwater; chemical activity.

\section{Introduction}

One of the critical components required in order to carry out safe and stable drilling of horizontal wellbores is the selection of accurate mud weight and chemistry. Before drilling the wellbore, in-situ stress tensor exists at equilibrium. Afterward, there is a redistribution of the stresses around the face of the wellbore. The mud weight must balance this re-distributed stresses, else, there will be severe drilling problems in the form of wellbore collapse and/or fracture (Aadnoy and Ong 2003). Wellbore collapse is an instability event that occurs at low well pressure, where rock materials fall into the wellbore, and through shear failure (Mitchell and Miska 2011). It leads to serious borehole cleaning problem that increases nonproductive time, and so it is very important to determine the mud weight necessary for its prevention. Wellbore instability in a horizontal wellbore can be very costly with the amount generally in exceeding $\$ 100 \mathrm{MM}$ per year worldwide (Dosunmu 2013; Mohammad 2012).

The shale section of horizontal wells can be very problematic. While the shale swells by reacting with water in the mud, drill cutting/caving continually falls unto the bottom of the wellbore causing increased difficulty in borehole cleaning. Many factors influence shale instability, which may include changes in mechanical stresses; swelling or hydration pressure; capillarity effect; cracks, micro-fissures and fractures; time-dependent pressure diffusion; and osmotic potentials. Rock strength is anisotropic (Choi et al 2015; Martenyanov et al 2017; Zhou et al 2018) because of preferential orientations of shale beddings, which are intervals of weak planes. In 
the concept of weak bedding planes, the beds are taken as intervals of weakness, where failure first occurs before translating to the rock matrix (Liu et al 2016) and propagates frequently along the lamina when initiated at flaw tips (Morgan and Einsten 2014). Thus, the inclusion of planes of weakness into wellbore stability analysis is a practical way of reducing drilling risks/costs, especially in horizontal wellbores. While the mud weight must be strong enough to prevent collapse, it must not be too large as to cause wellbore fracture. The chemical activities of mud and shale generate osmotic potential in the wellbore, as water molecules move through the semi-permeable membrane of shale. This should also be a consideration when carrying out wellbore stability analysis. Salt addition to mud has been recommended to improve wellbore collapse, the excess of which can lead to fracture (Fjær et al. 2008). This technology does not inform the drilling team on the range of salt addition needed to achieve realtime stability. That is why this current study is important, as it intends to do this. Therefore, a geomechanical study of this nature entails the determination of the critical mud weights to prevent wellbore failure by considering the most influencing factors. In this paper, mud chemical activity (or shale chemical activity) refers to the chemical activity of water in drilling mud (or in shale).

Deep water body may have a significant role to play with respect to wellbore stability during offshore drilling since the overburden stress comprises contributions from subsurface earth materials and seawater (Bourgoyne et al 1991). The variation in seawater level, due to global warming for example, affects the net overburden stress. The current trend in global warming can be a threat to the drilling industry, particularly if there is a significant increase in the rate at which the sea level rises. The current rate is about $3.2 \mathrm{~mm}$ /year (CSIRO 2018); although quite small, global warming still persists. For example, the global gas flaring rate rose by 3\% in 2018 according to a World Bank report (Nick Snow 2019). This increases the climate temperature, which can melt away much of the ice cap in the polar region, leading to a gradual increase in the depth of seawater. The corresponding change in the overburden gradient can then result in a change in the collapse gradient since the former gradient is a requirement in computing the latter. The possibility of having increased non-productive time becomes high. The industry does not want this kind of situation, especially when we consider that the cost of drilling a typical offshore well can reach up to $\$ 13 \mathrm{MM}$ (Kaiser 2009) depending on the water depth, offshore basin, type of rig and market condition. Nevertheless, there is currently little or no known research that considers the effect of the possible variations in water depth and mud chemical activity on wellbore collapse.

Wellbore engineers combine a constitutive stress equation, which shows the stress distributions around the wellbore, with an accurate rock failure criterion to determine successfully the critical mud weight (Chen et al 2015; Gholami et al. 2013; Martemyanov et al 2017; Zhou et al 2018). The rock failure criterion states the condition of principal stresses at the point when rocks fail. The selection of an accurate rock failure criterion is difficult and confusing (McLean and Addis 1990), mainly because models like Mohr-Coulomb criterion and HoekBrown criterion, which are 2D yield results that are quite reasonable while others like Mogi-Coulomb criterion and Drucker-Prager criterion, which are 3D yield practical results too. Nevertheless, the strengthening effect of the intermediate stress in a rock warrants the application of an accurate 3D model, especially in a polyaxial stress system. The classical method employed in any wellbore stability analysis is to calculate the stresses in the borehole coordinate system, input the data into borehole stress equations like the Kirsch`s equation, determine stress distribution at the face of the wellbore, implement a failure criterion appropriate to the formation under consideration, and compute the critical mud pressure (Chen et al 2015; Mitchell and Miska 2011; Martemyanov et al 2017). The effective principal stresses are used when applying the failure criterion because it is the failure at the matrix that is of importance. While this classical approach is sound, it has not been used to show whether a rise in water depth significantly affects collapse pressure during offshore drilling of horizontal wells, neither has it been used to specify a range of values for mud chemistry that can help to maintain stability especially in shale formations.

The main goal of this research is to predict wellbore collapse gradient in deep water horizontal wellbore, especially in a polyaxial stress system, and to consider the effects of mud chemical activity and variation in water depth on the pressure gradient in order to maintain a stable wellbore. Only the diffusion of mud water into (or out of) shale formation as a result of difference in activity will be considered. Subsequent study will consider shale and mud water reaction, which is time-dependent. A major component of the study is the use of the Mogi-Coulomb criterion. This is hardly used to discuss wellbore stability analysis when weak planes are involved; rather the choice is the Mohr-Coulomb criterion because of its simplicity. The reason for choosing the former failure criterion is that it is a linear form of the Mogi criterion, which is arguably the most representative of rock failure in a polyaxial stress 
state (Haimson and Chang 2005). Researchers have shown that the criterion yields better results when compared with the dimensions of wellbore breakout from caliper logs (Gholami et al. 2013; Song and Haimson 1997). The results of this study will assist in proper monitoring of the mud density of horizontal wellbores in offshore environments. It will help to guard the density design of mud. Thus, it is a targeted method for the reduction of non-productive time in horizontal wellbores.

\section{The constitutive stress models}

For stress concentration at the walls of the horizontal wellbore, an elasto-plastic model can be applied, but the most common approach is to use elastic models because of the fewer input parameters needed (Gholami et al. 2013). In generating such models the hollow cylinder model is applicable, which has the axial, radial and circumferential stresses. The mud weight inside the hole functions to maintain a stable wellbore. Generally, the mathematical expressions, in cylindrical coordinates, for the total stresses at the walls of deviated wellbores are given in the literature (Fjær et al. 2008). For horizontal wellbores, the expressions for the stresses are the following:

$$
\begin{gathered}
\sigma_{x}^{o}=\sigma_{v} \\
\sigma_{y}^{o}=(-\sin a)^{2} \sigma_{H}+(\cos a)^{2} \sigma_{h} \\
\sigma_{z}^{o}=(\cos a)^{2} \sigma_{H}+(\sin a)^{2} \sigma_{h} \\
\tau_{x y}^{o}=0 \\
\tau_{y z}^{o}=(-\sin a)(\cos a) \sigma_{H}+(\cos a)(\sin a) \sigma_{h} \\
\tau_{z x}^{o}=0
\end{gathered}
$$

where $\sigma_{v}$ is the vertical stress, $\sigma_{h}$ the minimum horizontal stress, and $\sigma_{H}$ is the maximum horizontal stress. $\sigma_{x}^{o}, \sigma_{y}^{o}, \sigma_{z}^{o}, \tau_{y}^{o}, \tau_{y}^{o}$ and $\tau_{x}^{o}$ are the virgin stress components under wellbore coordinate system with respect to the $\mathrm{x}, \mathrm{y}$, and $\mathrm{z}$ axes respectively. $\mu$ is Poisson`s ratio, $a$ is relative wellbore azimuth (difference between the azimuth of the maximum horizontal stress and the wellbore azimuth).

Mud circulation alters the stress state in the wellbore because of changes in the temperature of mud and formation (Maury and Sauzay 1987; Zhou et al. 1996), which can alter the tangential and axial stress by the same magnitude. The chemical interaction between the water in shale and mud generates an osmotic potential in the leaky membrane of the shale, with the following expression (Mody and Hale 1993):

$$
\Delta \Pi=-\frac{\sigma R T}{V_{w}} \ln \frac{a_{w, \text { shale }}}{a_{w . \text { mud }}}
$$

where $a_{w, \text { mud }}$ is the chemical activity of water in the mud, $a_{w, \text { shale }}$ the chemical activity of water in the shale, $\mathrm{R}$ the gas constant, $\Delta \Pi$ the osmotic potential of the mud-shale system, $V_{w}$ the molar volume of water, $\sigma$ the membrane potential, and $\mathrm{T}$ is temperature. This osmotic potential can act as a pressure increase resulting from the movement of water molecules from the mud into the shale or vice versa.

Mody and Hale developed a stress contribution based on this osmotic potential and added it to the axial and tangential stresses as shown in eq. (8):

$$
\Delta \Pi_{\text {shale, } \text { mud }}=\frac{\beta \Delta \Pi(1-2 \mu)}{(1-\mu)}
$$

where $\beta$ is Biot's poroelastic coefficient of the solid material and $\Delta \Pi_{\text {shale,mud }}$ is the stress contribution due to osmotic potential.

The stress term in eq. (8), added to the axial and tangential stresses, is meant to act as equivalence to a poroelastic stress contribution. The leakiness of the osmotic membrane is overcome using a membrane efficiency factor, $\sigma<1$, which for shale formation has values between 0.05 and 0.3 (Ewy and Stankovich 2002). The accurate value of the membrane efficiency must be used in order to avoid a computational error. Herein, an average value has been used. Apart from the mechanical and osmotic terms in the stress equations, thermal stresses are added to the constitutive equation (Fjær et al. 2008). Thus, the new expressions for the stress concentration in the horizontal wellbore in this study are the following:

$$
\begin{gathered}
\sigma_{r}=P_{w} \\
\sigma_{\theta}=\sigma_{x}^{o}+\sigma_{y}^{o}-2\left(\sigma_{x}^{o}-\sigma_{y}^{o}\right) \cos 2 \theta- \\
-4 \tau_{x y}^{o} \sin 2 \theta-P_{w}+\frac{\alpha_{t} E}{1-\mu}\left(T_{r}-T_{w}\right)+\frac{(1-2 \mu) \Delta \Pi \beta}{(1-\mu)} \\
\sigma_{z}=\sigma_{z}^{o}-2 \mu\left(\sigma_{x}^{o}-\sigma_{y}^{o}\right) \cos 2 \theta+ \\
+4 \mu \tau_{x y}^{o} \sin 2 \theta+\frac{\alpha_{t} E}{1-\mu}\left(T_{r}-T_{w}\right)+\frac{\beta(1-2 \mu) \Delta \Pi}{(1-\mu)}
\end{gathered}
$$


where $\sigma_{r}$ is the radial stress, $P_{w}$ the wellbore density, $\sigma_{\theta}$ the tangential stress, $\sigma_{z}$ the axial stress, E the Young's modulus, $\alpha_{t}$ the thermal constant, $T_{R}$ the formation temperature, $T_{w}$ the well temperature, and $\theta$ is the wellbore azimuth with reference to the $\mathrm{x}$-axis.

The stresses in eq. (1) to eq. (6) are not all principal stresses because eq. (5) can be non-zero. By defining a direction where the shear stresses varnish, the expressions for the maximum and intermediate normal principal stresses at the wellbore can be written as follows (Mitchell and Miska 2011):

$$
\begin{aligned}
& \sigma_{1}=0.5\left(\sigma_{\theta}+\sigma_{z}\right)+\sqrt{0.25\left(\sigma_{\theta}-\sigma_{z}\right)^{2}+\tau_{\theta z}^{2}} \\
& \sigma_{2}=0.5\left(\sigma_{\theta}+\sigma_{z}\right)-\sqrt{0.25\left(\sigma_{\theta}-\sigma_{z}\right)^{2}+\tau_{\theta z}^{2}}
\end{aligned}
$$

where $\sigma_{1}$ and $\sigma_{2}$ are the maximum principal stress and intermediate principal stress, respectively.

In order to build upon the concept of the effect of seawater, use is made of the Fjær et al. (2008) concept of the wellbore pressure in an offshore environment. The critical mud density in such locality comprises contribution from the water depth and formation depth. Incorporating these components, they developed the expression for the critical wellbore density as follows:

$$
\rho_{w, c r i t}=\frac{\rho_{c r i t}^{o} Z_{f n}+\rho_{w} Z_{w}}{Z_{f n}+Z_{w}}
$$

where $\rho_{w, c r i t}^{o}$ is the critical mud density without water depth, $\rho_{w, c r i t}$ the critical mud density while considering the water depth, $\rho_{w}$ the density of water, $Z_{w}$ the water depth, and $Z_{f i n}$ the depth from the seafloor.

Rewriting eq. (14) in terms of density in pressure per depth, the following expression is posed for the critical wellbore pressure:

$$
P_{w, c r i t}=\frac{P_{w c}^{o} Z_{f m}+P_{s w} Z_{w}}{Z+Z}
$$

where $P_{s v}$ is the pressure gradient of seawater, $P_{w}$, crit the critical collapse pressure when water depth is considered, $P_{w}^{o}$ the wellbore pressure without water depth, and $Z_{f m}$ and $Z_{w}$ are as defined as in eq. (14).

Typically, wellbore stability analysis may or may not consider time-dependent effects due to diffusion. When diffusion effects are considered, the poroelasticity theory couple stresses and pore-pressure with fluid diffusion playing an important role (Shi et al 2016). More parameters like porosity, permeability, and pore pressurestress coupling term are then introduced, thereby making the analysis more complex to solve.

\section{Methodology of study and failure character of weak bedding plane}

This study follows the classical rock mechanics method for geomechanical studies (Chen et al. 2015; Gholami et al. 2013; Zhou et al. 2018), by first obtaining the stress concentration at the wellbore faces, and then applying the Mogi-Coulomb failure criterion, which is the following expression between octahedral shear stress and mean normal stress (Chen et al 2015):

$$
\tau_{o c t}=a_{o}+b \sigma_{m}
$$

where $\tau_{o c t}$ is the octahedral shear stress, $a_{o}$ the constant related to cohesion, $b$ the constant related to friction angle and $\sigma_{m}$ is the mean effective stress acting on the failure plane.

From the relationship between the octahedral shear stress and the second deviator stress invariant (Colmenare and Zoback 2002), a form of the Mogi-Coulomb criterion is presented as follows:

$$
\sqrt{J_{2}}=r+R \sigma_{m, 2}
$$

Where $\mathrm{r}$ is a constant related to cohesion, $\mathrm{R}$ a constant related to friction angle, $\widetilde{\sigma}_{m, 2}$ the effective mean stress acting on the failure plane, and $\sqrt{J_{2}}$ is the second invariant of stress deviator.

In order to obtain the parameters in eq. (17), so as to make the analysis consistent with conventional approach, a tri-axial stress condition was assumed and then compared with one of the expressions of the MohrCoulomb criterion (Al-Ajmi 2006), yielding the following:

$$
\begin{aligned}
& r=\frac{2 c \cos \phi}{\sqrt{3}} \\
& R=\frac{2 \sin \phi}{\sqrt{3}}
\end{aligned}
$$

where $\mathrm{c}$ is cohesion and $\phi$ is friction angle. 
As to the inclusion of planes of weakness, this study follows the classical approach (Chen et al 2015; Zhou et al 2018), but rather applies the Mogi-Coulomb criterion instead of the Mohr-Coulomb to maintain consistency of the research. The assumption is that the weak planes fail first by obeying the same rule as the rock mass when present. Hence, the failure criterion for the weak bedding planes follows the form of eq. (17):

$$
\sqrt{J_{2}}=r_{w}+R_{w} \sigma_{m, 2}
$$

where $r_{w}$ is a constant related to the cohesion of the weak bed, $R_{w}$ a constant related to the internal friction angle of the weak planes. Relating eq. (20) to the conventional Mohr-Coulomb criterion helps to maintain consistency and enables the same condition for the angles between failure planes`normal and the maximum principal stress to be applicable.

The effects of mechanical stresses, thermal stress and chemical interaction between mud and shale were incorporated while developing the constitutive stress. Equation (15) was used to include the effect of variation in depth of seawater. The convention for depth reference is that the formation depth is from the seafloor downward, water depth is from the seafloor up to the derrick floor and air gap is neglected.

\section{Analysis and discussion of result}

The expressions for the second deviator stress invariant and the effective mean stress are respectively given by eq. (21) and eq. (22) (Colmenare and Zoback 2002):

$$
J_{2}=\frac{1}{6}\left(\left(\sigma_{1}-\sigma_{2}\right)^{2}+\left(\sigma_{1}-\sigma_{3}\right)^{2}+\left(\sigma_{2}-\sigma_{3}\right)^{2}\right)
$$

where $\sigma_{1}$ is the maximum principal stress, $\sigma_{2}$ the intermediate principal stress, and $\sigma_{3}$ is the minimum intermediate stress.

$$
\sigma_{m, 2}=\frac{\sigma_{1}+\sigma_{3}-2 P_{p}}{2}
$$

where $P_{p}$ is the pore pressure in the rock. The substitution of eq. (18) - eq. (21) into eq. (17) yields the following reduced expression:

$$
\begin{aligned}
& 2 \sigma_{1}^{2}+2 \sigma_{3}^{2}+2 \sigma_{2}^{2}-2 \sigma_{1} \sigma_{2}-2 \sigma_{1} \sigma_{3}- \\
& -2 \sigma_{2} \sigma_{3}-a_{1}-b_{1} \sigma_{m, 2}-C_{1} \sigma_{m, 2}^{2}=0 \\
& a_{1}=8 c^{2} \cos ^{2} \phi \\
& b_{1}=16 c \sin \phi \cos \phi \\
& C_{1}=8 \sin ^{2} \phi
\end{aligned}
$$

\subsection{Critical mud weight to prevent wellbore collapse in horizontal wellbores.}

The following substitutions are made in order to ease the computation in this study:

$$
\begin{gathered}
A=\sigma_{x}^{o}+\sigma_{y}^{o}-2\left(\sigma_{x}^{o}-\sigma_{y}^{o}\right) \cos 2 \theta- \\
-4 \tau_{x y}^{o} \sin 2 \theta+\frac{E \alpha_{t}}{1-\mu}\left(T_{w}-T_{R}\right)+\frac{(1-2 \mu) \beta}{1-\mu} \Delta \Pi \\
B=\sigma_{z}^{o}-\mu\left[2\left(\sigma_{x}^{o}-\sigma_{y}^{o}\right) \cos 2 \theta+\right. \\
\left.+4 \tau_{x y}^{o} \sin 2 \theta\right]+\frac{E \alpha_{t}}{1-\mu}\left(T_{W}-T_{R}\right)+\frac{(1-2 \mu) \beta}{1-\mu} \Delta \Pi
\end{gathered}
$$

Then the maximum and intermediate principal stresses in eq. (12) and eq. (13), reduce as follows:

$$
\begin{aligned}
& \sigma_{1}=0.5\left(A+B-P_{w}\right)+\sqrt{0.25\left(A-B-P_{w}\right)^{2}+\tau_{\theta z}^{2}} \\
& \sigma_{2}=0.5\left(A+B-P_{w}\right)-\sqrt{0.25\left(A-B-P_{w}\right)^{2}+\tau_{\theta z}^{2}}
\end{aligned}
$$

With the shear mode that allows the tangential stress as a maximum and the radial stress as a minimum (Gholami et al 2013), $\sigma_{1}=\sigma_{\theta}, \sigma_{2}=\sigma_{z}$, and $\sigma_{3}=\sigma_{r}$. The expression in eq. (23) reduces as follows:

$$
6 P_{w}^{2}-6 A P_{w}+S=0
$$

$$
\begin{gathered}
S=2\left(A^{2}+B^{2}-A B\right)-a_{1}-0.5 b_{1} A+ \\
+b P_{p}-0.25 A^{2} C_{1}+A P_{p} C_{1}-P_{p}^{2} C_{1}+6 \tau_{\theta Z}^{2}
\end{gathered}
$$


The solution to eq. (31) is the following model:

$$
P_{w}=\frac{6 A \pm \sqrt{36 A^{2}-24 S}}{12}
$$

The lower limit of eq. (33) gives the mud weight to prevent wellbore collapse since it is the first value to encounter, thus it is safer to drill with it. It yields the value for the critical mud weight without considering the seawater depth. The application of eq. (15) yields the critical mud weight in a deep-water formation. If there are data for weak bed in the analysis, such data will be presented for the cohesion and friction angle and the analysis will be amenable to eq. (33). NB: Eq. (33) may yield complex roots based on the value of the discriminant, $36 A^{2}-24 S$. The combination of the parameters in eq. (32) becomes critical in obtaining such complex roots. It is not intended to consider the nature of the roots obtained in this study; such analysis may be kept for future research. The values obtained from this study are given in terms of the pressure gradient, which is pressure per depth of interest. It may be referred to as critical mud density, which is the equivalent weight of the mud used in drilling the wellbore.

\subsection{Result testing and discussion.}

Table 1 shows the data for well A1 at $1524 \mathrm{~m}$, with the azimuth of the maximum horizontal stress of $\mathrm{N} 180^{\circ} \mathrm{E}$. The result indicates a critical mud density of $12.658 \mathrm{kPa} / \mathrm{m}$ at the specified conditions. This mud weight is quite larger than the pore pressure indicating that an overbalance drilling for the wellbore results in a stable wellbore. Including a plane of weakness with a cohesion of 2068.427 $\mathrm{kPa}$ and a friction angle of $25^{\circ}$ yields a collapse gradient of $14.2907 \mathrm{kPa} / \mathrm{m}$, which is an increase from the previous result. This shows that higher mud weight is needed to successfully drill through weak planes.

\subsection{The effects of water depth on collapse gradient}

A two-fold presentation is made here. Irrespective of how gradual it may occur, it is possible to have an increase in the seawater level resulting from, say, the global warming effect of ice cap melting. The variation in mud density with an increase in water depth with the current sea level rate is shown in figure1. Without the water depth of 152.4 $\mathrm{m}$, the mud density is equivalent to an onshore wellbore
Table 1: Data for well A1 used in the study.

\begin{tabular}{ll}
\hline$\sigma_{v}=22.621 \mathrm{kPa} / \mathrm{m}$ & $\phi=32^{\circ}$ \\
$\sigma_{H}=19.228 \mathrm{kPa} / \mathrm{m}$ & $Z=1524 \mathrm{~m}$ \\
$\sigma_{h}=18.096 \mathrm{kPa} / \mathrm{m}$ & $a_{w, \text { shale }}=0.8$ \\
$p_{o}=10.179 \mathrm{kPa} / \mathrm{m}$ & $a_{w, \text { mud }}=0.8$ \\
$c=4826.33 \mathrm{kPa}$ & $\theta=\mathrm{NOE}$ \\
$\mu=0.28$ & $Z_{w}=152.4 \mathrm{~m}$ \\
\hline
\end{tabular}

with a critical mud density of $12.919 \mathrm{kPa} / \mathrm{m}$. Although the rate at which the sea level rises is small, the global warming trend indicates that the wellbore collapse is not constant, but rather changes (reduces) gradually. With the current rate, drilling in an offshore platform for about 50 days will reduce the collapse gradient only fractionally. If the current rate of change in the sea level speeds up, the wellbore collapse gradient will reduce proportionately. The increase in water level causes little compaction of the rock, thus making it denser. As the rock becomes denser, its tensile strength reduces while its compressive strength increases and this causes the collapse gradient to reduce.

Figure 2 shows the variation of the collapse gradient from the seafloor to the depth of interest in the formation itself for water depths of 76, 152.444 and $304.878 \mathrm{~m}$. It is observed that at the seafloor, the values of the collapse gradient, for the different seawater depths, all approach that of seawater gradient, which is $10.046 \mathrm{kPa} / \mathrm{m}$. This allows the use of the technique of dual gradient drilling within the marine riser (Fjær et al 2008). At a shallower depth of about $200 \mathrm{~m}$ from the seafloor, the collapse gradient increases drastically before gradually changing in values at deeper depth. It may be important to use values of mud density that are just above the value of seawater density within this zone, before transitioning into deeper regions, where heavier mud density is used. It indicates that the values of the collapse gradient for a water depth of $304.878 \mathrm{~m}$ are lower than those of the $152.4439 \mathrm{~m}$ water depth, while those of the latter are lower than for $76 \mathrm{~m}$ water depth, indicating that the lower the water depth, the heavier the mud density to use in drilling deeper into the formation. This confirms that the effect of water depth is to reduce the collapse gradient.

The highest water depth has the smallest increase in the collapse gradient at shallower depths of the seafloor and the largest increase at deeper depths. For example, between 100 and $500 \mathrm{~m}$ below the seafloor, there is an increase in collapse gradient of 1.0956 for a water depth of $76 \mathrm{~m}, 0.9586$ for a water depth of $152.44 \mathrm{~m}$ and 0.6972 for a water depth of $304.878 \mathrm{~m}$, while between 3000 and 3500 


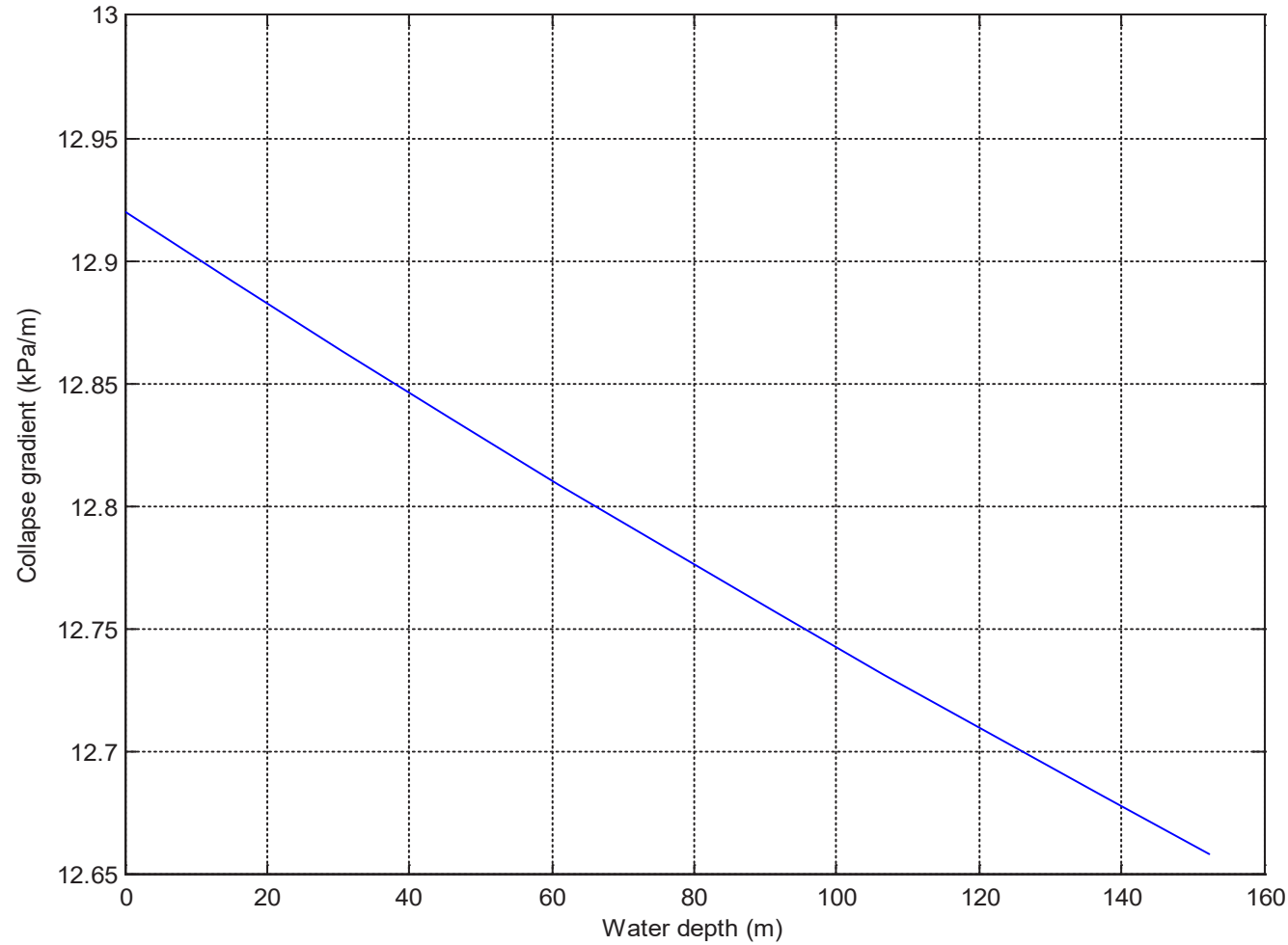

Figure 1- Effect of water depth on the critical mud weight

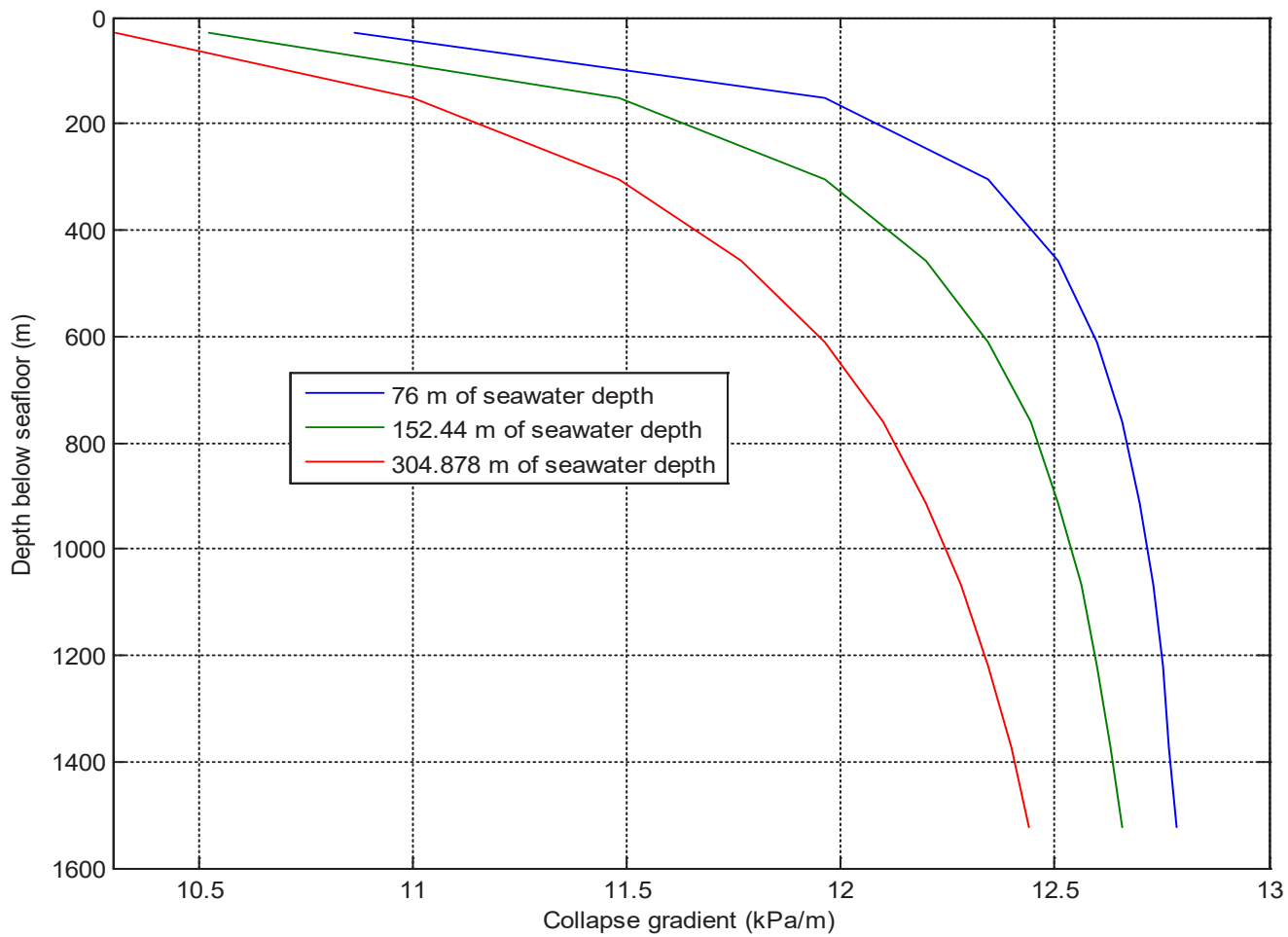

Figure 2-Variation of wellbore collapse within the formation due to the column of water 


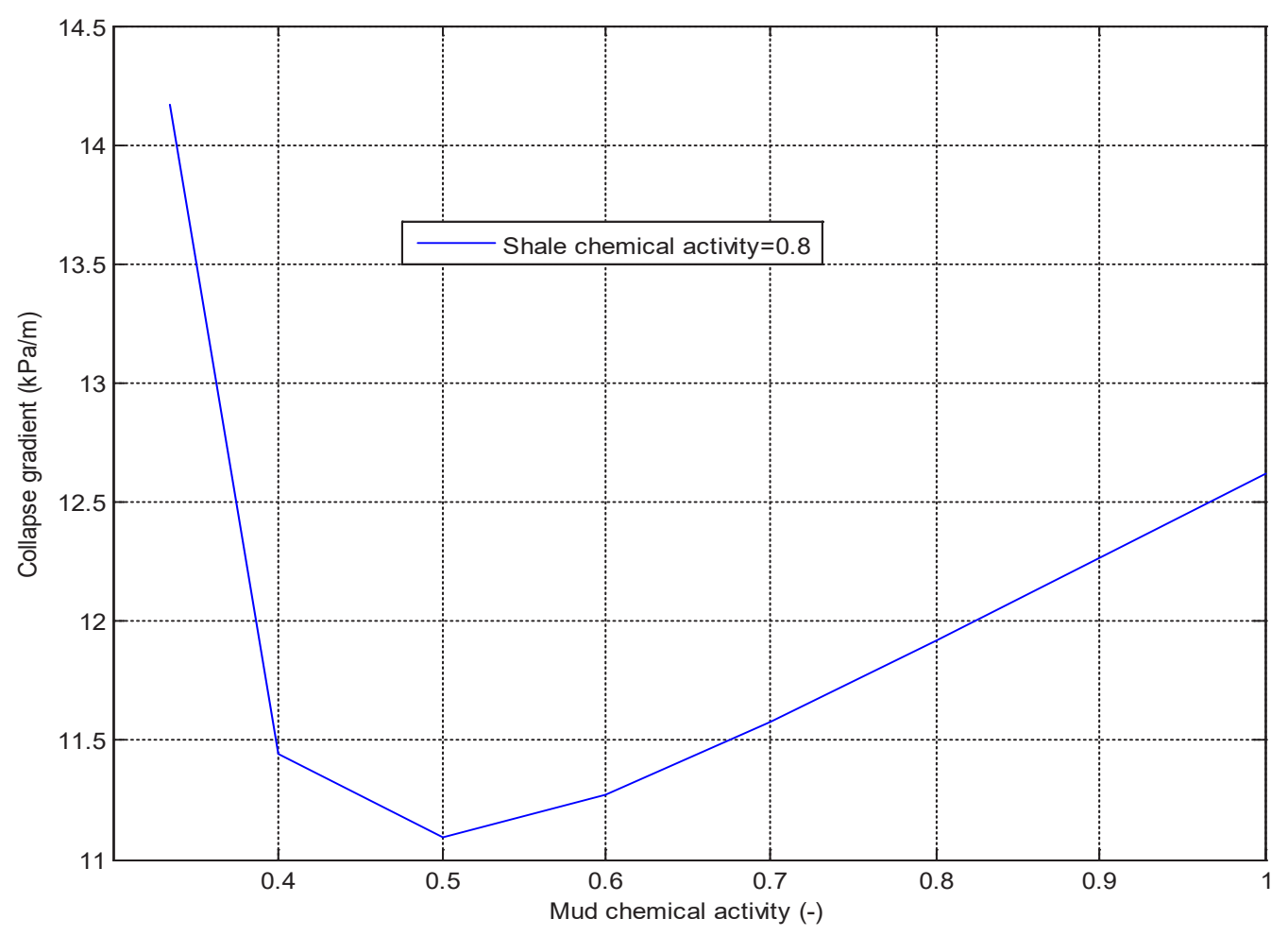

Figure 3: Effect of mud chemical activity on the critical mud weight

$\mathrm{m}$ below the seafloor, there is an increase of $0.0295,0.0513$ and 0.0798 for $76,152.44$ and $304.878 \mathrm{~m}$ respectively.

\subsection{The effects of mud chemical activity on the collapse gradient}

Figure 3 shows a complex relationship between the critical mud weight (in $\mathrm{kPa} / \mathrm{m}$ ) and mud chemical activity, which indicates that the wellbore stability is flanked by unstable regions resulting from low salt and excess salt addition into mud. In order to obtain the trend, data in Table 1 were applied using the water depth of $152.44 \mathrm{~m}$ with a shale chemical activity of 0.8 , while varying the mud chemical activity from 0.1 to 1 . Values for wellbore collapse are indeterminate for mud activities between 0 and 0.3. When the mud chemical activity is higher (lower salt content) than that of shale, water has the tendency to flow into the shale formation, leading to swelling of the rock and then wellbore collapse.

The mud weight must be increased in order to balance this effect. A lower value of the mud chemical activity results in a positive value for the osmotic potential, meaning water moves toward the wellbore, rather than shale. This prevents shale swelling and the wellbore tends to be stable. This is consistent with the results obtained in the literature (Fjær et al. 2008; Mitchell and Miska 2011; Zhang et al. 2015), but the limit of the salt addition that can cause wellbore fracture is not known. Nevertheless, the graph shows that as the mud chemical activity becomes lower with more salt addition, a virtually unstable region ensues. Here, at values lower than 0.5 , the critical mud density seems to increase. It is a virtual effect caused by free water leaving the porous spaces of the shale, leading to shrinking and possible induction of cracks. The total weight increase in the wellbore due to the inflow of water, together with the induced cracks then has the tendency to cause wellbore fracture. Hence, the value of 0.5 can be seen as the critical limit for salt added into the mud for this wellbore. Thus, it is safe to say that a salt addition scheme that leads to reduction of mud chemical activity to about $37.5 \%$ of the initial value is the limit employable in a practical situation, beyond which the salt addition scheme can lead to wellbore fracture. A similar set of results is obtained by varying the value of shale chemical activity as shown in Figure 4.

There seems to be a convergence of the collapse gradient at a mud activity of 0.5 for the three trends shown. Shale with the chemical activity of 0.8 seems to have lesser complexities than when the value is higher at 


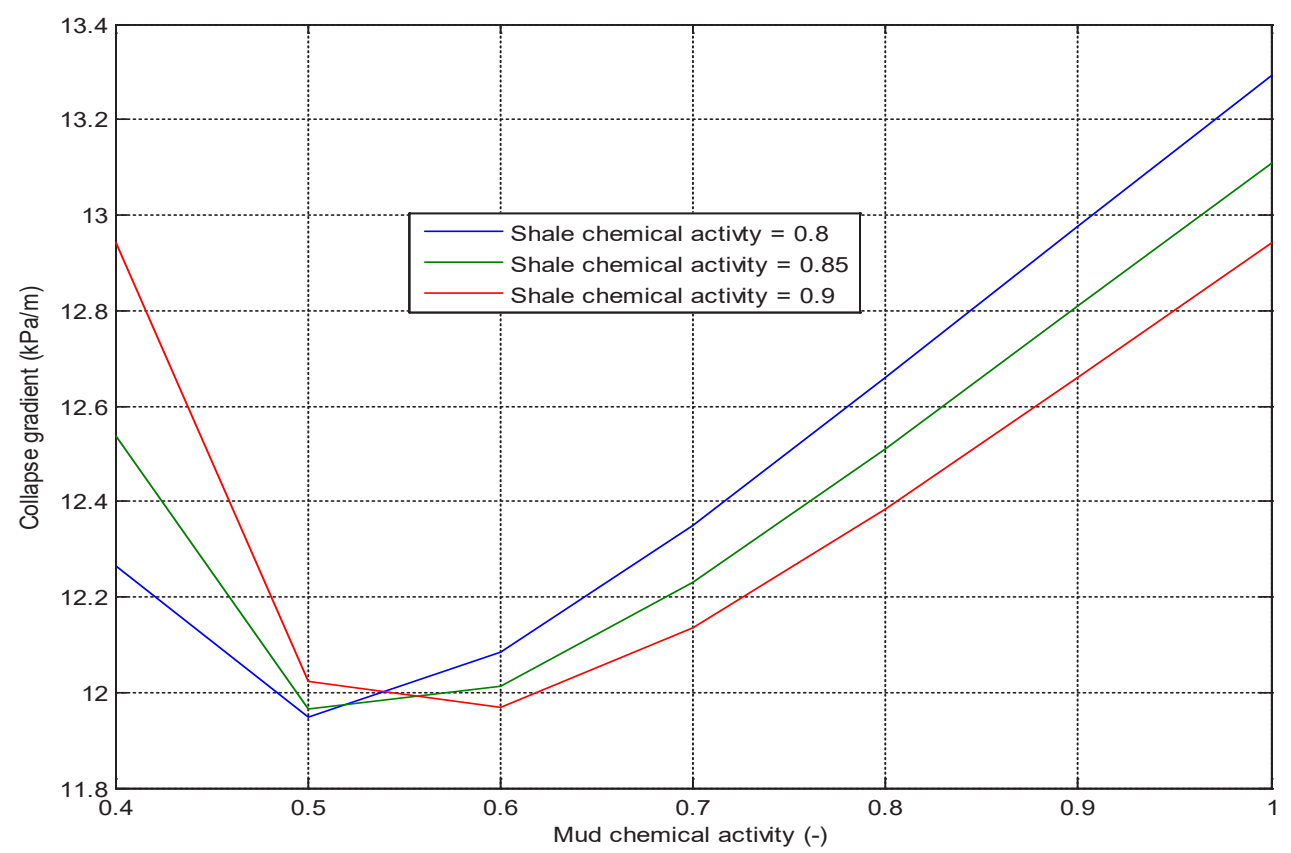

Figure 4: Effect of mud chemical activity on the collapse gradient for different shale chemical activities.

0.9 but requires a higher mud density to obtain a stable wellbore. For the three trends, the limiting value of the reduction in mud chemical activity is about $37.5 \%$.

\section{Conclusions}

Mud design for practical drilling of horizontal wellbores in offshore environments can yield cost-efficient results by including more controlling mechanisms into the analysis. The salt content of drilling mud has to be known and recorded before embarking on the operation, so that on an encounter with a reactive interval, it will be possible to moderate the mud chemical activity using the recommendation from this study. Sea level indicators are required to be installed into the drilling platform, so that changes in the water depth can be measured and noted, although currently, it is very minimal. A conscious effort toward curtailing gas flaring is needed by the major companies in order to reduce the greenhouse effects. A summary of the main points drawn from the study is as follows:

- The effect of water depth in the drilling of horizontal wellbore is to significantly decrease the collapse gradient requirement, with further reduction possible if the sea level rises.
- The current level of seawater rise does not significantly affect the wellbore collapse gradient.

- Reduction in mud chemical activity by the addition of salts reduces the prevalence of wellbore collapse, but a targeted reduction to about $37.5 \%$ of the initial value is safe.

- Higher difference between mud and shale chemical activities corresponds to higher complexities in the wellbore.

\section{References}

[1] Aadnoy, B. S., Ong, S., 2003. Introduction to special issue on Borehole Stability. J Petrol Sci Eng, 38[3-4], 79-82.

[2] Adewale Dosunmu, 2013. Fundamentals of Petroleum Geomechanics and Wellbore Stability in Well Design and Construction, SPE Short Course held at SPE/NAICE Conference, Lagos, Nigeria.

[3] Al-Ajmi, A.M., 2006.Wellbore stability analysis based on a new true-triaxial failure criterion, TRITA-LWR Ph.D. Thesis 1026.

[4] Bourgoyne, A.T., Millheim, K.K., Chenevert, M.E., Young, F.S., 1991. Applied Drilling Engineering, SPE Textbook Series, Vol.5, 246-259.

[5] Colmenare L.B., Zoback M.D., 2002, A statistical evaluation of intact rock failure criteria constrained by polyaxial data for five different rocks, IJRMMS, 39, p. 699.

[6] Chen, P., Tianshou, M., Hongqua, X., 2015. A Collapse Pressure Prediction Model for horizontal shale gas wells with multiple weak planes, Natural Gas Industry B. 2(1), 101-107. 
[7] Choi, S-B., Mim, K-B., Kim, T., Jeon, S. 2015. Experimental investigation on anisotropic characteristics of Boreyong shale in Korea. In: 13th ISRM International Congress of Rock Mechanics, 2015. International Society for Rock Mechanics.

[8] CSIRO, 2018. "Historical Sea level changes: Last decades", www.cmar.csiro.ac. Retrieved 2018-08-26.

[9] Ewy, R.T., Stankovich, R.J., 2002.”Shale-fluid interaction measured under simulated downhole condition". SPE/ISRM 78160. In: SPE/ISRM Rock Mech. Conference, Irving, Texas, 20-23 Oct.

[10] Fjær, E., Holt, R. M., Horsrud, P., et al., 2008. Petroleum Related Rock Mechanics, $2^{\text {nd }}$ Edition, Elsevier, Amsterdam, pp: 146-149, 323-334.

[11] Gholami, R., Moradzadeh, A., Rasouli, V., Hanachi, J., 2013. Practical application of Failure criteria in determining safe mud weight windows in drilling operations, J Rock Mech Geotech Eng. 55. 1-13. http://dx.doi.org/10.1016/jrmge.2013.11.002

[12] Haimson, B., Chang, C., 2005. Brittle fracture in two crystalline rocks under true triaxial compressive stresses. Geol Soc Special Pub, [240], 47-59.

[13] Kaiser, M.J., 2009. Modeling the time and cost to drill an offshore well, Energy, 34, 1097-1112.

[14] Liu, X., Zeng, W., Liang, L., Lei, M., 2016. Wellbore stability analysis for horizontal wells in shale formations. J. Nat. Gas Sci. Eng. 31, 1-8. https://doi.org/10.1016/j.jngse.2016.02.061.

[15] Martemyanov, A., Lukin, S., Ovcharenko, Y., Zhukov, V., Andrianov Y., Vereshchagin S., Ereemev A., Konchenko, A., Tatur, O., Yuferova, A., 2017. Analytic Modeling for Wellbore Stability Analysis, Procedia Struct. Integrity. Vol. 6, 292-300. https://doi.org/10.1016/j.prostr.2017.11.045

[16] Maury, V. M., Sauzay, J. M. G., 1987. Borehole instability: Case histories, rock mechanics approach and results. In: Proc SPE/ IADC Drilling Conf, New Orleans, March 15-18. SPE 16051.

[17] McLean, M., Addis, M., 1990. Wellbore stability analysis: a review of current methods of analysis \& their field application. In: Proc IADC/SPE Drilling Conf, Houston, Feb. 27-Mar 2. SPE 19941.

[18] Mitchell, R.F., Miska, S.Z., 2011. FUNDAMENTALS OF DRILLING ENGINEERING, SPE TEXTBOOK SERIES, Vol 12, pp. 61-79.

[19] Mody, F.K., Hale, A.H., 1993. "Borehole stability model to couple the mechanics and chemistry of drilling fluid shale interaction”. J. Pet Tech. 45, 1093-1101.

[20] Morgan, S., Einstein, H., 2014. The effect of bedding plane orientation on crack propagation and coalescence in shale. In: 48th US Rock Mechanics/Geomechanics Symposium. ARMA.

[21] Mohammad, E.Z., 2012. Mechanical and physical-chemical aspects of wellbore stability during drilling operations. J. Petrol. Sci. Eng., 82-83: 120-124.

[22] Nick, S., 2019. World Bank: Global gas flaring up 3\% in 2018. Oil and Gas Journal. www.ogj.com.

[23] Shi, X., Yang, X., Meng, Y., Li, G., 2016. Wellbore Stability Analysis in Chemically Active Shale Formations, Thermal Science, 20 (3), 911-917.

[24] Song, I., Haimson, B. C., 1997. Polyaxial strength criteria and their use in estimating in situ stress magnitudes from borehole breakout dimensions. IJRMMS, 34 [3-4].

[25] Zhang, Q., Wenyu, J., Xiangyu, F., 2015. A review of the shale wellbore stability mechanism based on mechanical-chemical coupling theories, Petroleum 1(2015) 91-96.
[26] Zhou, J., He, S., Tang, M., Huang, Z., Chen, Y., Chi, J., Zhu, Y., Yuan, P., 2018. Analysis of wellbore stability considering the effects of bedding planes and anisotropic seepage during drilling horizontal wells in the laminated formation, JPSE, 170 (2018), 507-524.

[27] Zhou, S. H., Hillis, R. R., Sandiford, M., 1996. On the mechanical stability of inclined wellbores. SPE Drilling Comp, $11[2], 67-73$. 